\title{
Research on Ecological Benefits Compensation for Forest Resource in State-Owned Forest Area
}

\author{
Mei-Yan LIU \\ ${ }^{1}$ Management Faculty of Harbin Finance University, Harbin, PR China \\ a50428840@qq.com
}

\section{Keywords: State-owned forest area, Ecological benefits, Compensation}

\begin{abstract}
It's one of the results to trace high-speed development of economy for a long period in the country that the climate turns worse. People start to pay attention to the ecological issues when the economy was developed to a certain level. Now it's a main aspect to establish ecological civilization in the national developing strategy. It is demanded in related documentation to establish systematical and complete institutional system of ecological civilization and protect the ecological environment with the system. Perfect natural resources property right system and purpose regulation system; delimit ecological red line; implement resources paid use system and ecological compensation system; and reform ecological environment protection management system. This paper provides evidences for ecological compensation in forest area through explaining the existing issues and legislation in ecological benefits compensation for forest resource in state-owned forest area.

The forest production combines lots of labor, it is a kind of labor product with both use value and value. At the same time, forest operators are able to create ecological function value of the forests, this also reflects the relationship between input and output of forest resources. The forest resource is tangible product and can be measured by currency while it's ecological function is intangible and can't be measured by currency, tangible product is the formation basis of intangible product. Forests provide diversified services to people by directly or indirectly, tangible or intangible ways to satisfy the various needs of people and bring economic benefits and social benefits for the residents. Therefore we say forests have the feature of externality. We need to transfer externality in some way to show the balance of benefit, and promote all the society to take part in the process of ecological maintain, to keep sustainable development and using of forests and ecological resources.
\end{abstract}

\section{Introduction of Forest Ecological Benefits Compensation}

Ecological compensation is a set of policy to adjust the relationship of related parts mainly by economy method aimed at protecting and sustainable using ecological system. More narrowly, ecological compensation mechanism is a set of public policy aimed at protecting the ecology environment and promoting the human and environment harmonious development, according to the value of the ecology system service, the cost of ecology protection, the cost of development chance, using the government and market ways to adjust the relationship of benefit related parties. The scope of the definition includes forest ecological compensation, wetland ecological compensation, meadow ecological compensation, ocean current ecological compensation and mine ecological compensation, etc. As the environment getting worse today, the demand for a better living space get more and more urgent, the research on the forest ecological compensation has increased a lot recently, it's mainly focus on the research of legislative level and theoretical level as well as measures of compensation standard and compensation method.

Forest ecological compensation is a kind of comprehensive means, the main target of it is to balance and promote the benefit of forest user and protector, namely, the process for the government as the main body to give corresponding economic compensation to the operators and the forestation workers. This compensation include the compensation to the ecological environment, to the personal forestation worker and investment to the important area and object with high ecological value. 
In the related laws and policies in China, it is clearly defined that ecological compensation includes four aspects: first, compensate the environment itself; second, provide cost for ecological environment, it means to control the destruction of environment by using economic means; third, compensate for personal ecological environment protecting behavior of abandon gaining from forest with the opportunity cost; forth, the economic investment to the area with great value in ecology. Among the above, the first one is from the aspect of ecology and the other three are from the aspect of economy, they are economic means and mechanism in ecology, environment and nature resource protection.

\section{The Main Issues of Forest Ecological Benefits Compensation}

It's in the initial stage for forest ecological benefits compensation in our country, compensation subject, object and compensation mechanismall have issues like nonstandard and faulty, etc.

\section{The Scope of Forest Ecological Compensation is too Narrow}

For now, the scope of forests ecological compensation is mostly limited in returning the grain plots to forestry, the nature forests protection project and the important area ecological public welfare forest compensation, while there is few compensation project in other fields. Look at the world, many other countries have covered large scale in forests ecological compensation. For example, the United States implements farm idling plan; some countries in Europe Union apply strict soil and water protection measures and maintain a diversified protection about ridge of field; Costa Ricahas established a confirmable trade compensation system to protect the local forests and reduce the release amount of carbon dioxide; Brazil makes rules, at one side to recover the function-faded forests, and expands the protected area, at the same time establish policy to private the nature legacy, and collect the increment value duty. Denmark, Sweden, Holland and Germany and many other countries expend the type of tax, for example, begin to collect tax of environment. Therefore, compared with many other countries, there are a lot of work to do and a lot of compensation problem urgently to be solved for our countries.

\section{The Capital Channel of Forest Ecological Compensation Isunitary}

The payment of ecological compensation in China is implemented mainly by government's finance transfer payment and special funds now with the transfer payment occupied the most rate of funds channel. From the payment measure of finance transfer, the longitudinal finance transfer payment plays the leading role. Namely, it's the payment method from the top to the bottom, center to local, higher competent department to lower competent department, so it is rarely seen between regions, different social groups and the beneficiary side of the forest ecological environment. It's obviously that the payment was taken by the central or the higher government, it's entirely different with the original intention which is "who gains who pay" policy. It needs large amount of funds to maintain the normal grow of the forest and develop the forest ecological project and it is possible to affect the process and the quality of the forest ecological project if only rely on the country's or the government's investment to solve the problems. To avoid the above situation, it needs to look for funds channels positively, collect expense needed from various sides to make sure the forest ecology project goes persistently and smoothly.

\section{The Standard of Forest Ecological Compensation is not Reasonable}

In recent years, the experts and scholars mainly adapt ecological footprint method and ecological construction cost method for quantitative research on ecological compensation. The ecological footprint method needs the trade data of different areas, it fits to the estimate calculation in a large scale of area; it lacks of reality when using the ecological construction cost method to do cost accounting, as the long period of forest, lots of uncertain facts, unfitting of simple accumulation of different times. Now the standards of the forest ecological compensation basically apply "one-size-fits-all" policy. But the reality is that the forest resource's difference is obvious due to various region and environment. No matter the project of returning the grain plots to forestry or the 
important area ecological welfare forest, the contribution to ecological benefit is different of different regions of forest.

\section{Lack of Marketization Mechanism}

Marketization refers to a state using market as basic measure to solve social, political and economic issues, it means loosing of government control and property privatization. To be short, it's a state of co-ordination of supply and demand by using price function, the fact is expanding the market and open the content. At present, we have no reliable pattern in forest ecological benefits marketization and still in a exploring period, some market exchange cases are apparent occasionally and haven't formed large scale and programmed process, and the scope mostlyishydrological services trade and carbon trade. It's lack in systematic and complete research on deep forest ecological benefit market related subject, exchange object, exchange scale, amount, process, etc.

\section{Lack of Scientific Calculation Method System}

The forest ecological compensation is limited in technical aspect for it's not clear set in what standard to use in assess of forest ecological benefit. The theories of assessing forest ecological benefit and measures are in the state of exploring, an accepted and perfect calculation frame is not set yet.

\section{The Policies of Forest Ecological Compensation are Relatively Behind}

There is no special legislation in forest ecological compensation, the applied measures of forest ecological compensation are mostly emergency legislation. When each region carries out the work of forest ecological compensation, it's very hard to guarantee smooth and effective work activities because there is no powerful support by law.

\section{The Policy and Legislation Suggestions of Forests Ecological Compensation}

\section{Clear the Evidence of Ecological Compensation}

Combined with China's property rights system scientifically, in accordance with the right subjects and their benefit losses which provide forest ecological services in the forest resource utilization, the compensation objects and standards shall be confirmed. Specifically, the compensation is based on the compensation for the benefit losses of the rights owners, which compensates for those benefit losses in the forest resource utilization for the benefit of ecological service and public purpose. This compensation is for the benefit losses of rights holders resulting from the ecological service of the forest, not for the value from the ecological effect of the forest.

\section{The Definition for the Compensation Policy and Law}

We must further define the subject and object of compensation. The subject of compensation is divided into central level and local level. At the national level, such as national nature reserve, national forest park, national key protection zone of forest, etc. it must correspond to the division of national main functional area. For the national and key protection zone of forest resources, the priority should be mainly based on national compensations. In terms of the way of compensation, financial transfer payment, compensation with material object or other methods of compensation should be made clear in relevant legislations and policies. On the other hand, the standard of compensation amount should be clearly set in accordance with the large area and different types.

\section{Multiple Forms Simultaneous Development of Ecological Compensation}

For the important areas such as nature protection area and other relatively small national key ecological protection zone, to solve the problem in a fundamental way, the ownership and the right to use of forest resources should be gradually "purchased by state ". Regarding to the marketable function of forest ecological service, the economic loss of owners and runners should be alleviated through marketization in the process of ecological building. On the basis of protecting ecological functions, limitations on the use of resources should be loosened up in accordance with deficiency 
in ecological compensation of provincial level so that the conflicts between protection and utilization and that between protection and economic development be solved, and the conflict of externality and interest should be alleviated as much as possible.

\section{Better Combination of the Compensation and Protection Management}

Compensation without management could not upgrade the forest operation management level, and the ecological system and resource management level could not be guaranteed effectively, either. When compensating the forest resources, it shall consider the interest relation between the compensation subjects and forest resources beyond compensation and how to motivate subjects receiving compensation to operate and manage the forest resources. On the one hand, it shall establish sound combination between protection and compensation through the incentive mechanism; on the other hand, it should also divide the public welfare forests appropriately to avoid the unlimited scope of compensation. It also is the important issue for handling the combination between compensation and management.

\section{References:}

[1] Zhang Qi. Study on laws and regulations of cultivated land ecological compensation in our country. Yang Ling: North West Agriculture and Forestry University, 2012

[2] Niu Haipeng. Method of measuring ecological and social benefits of cultivated land and its application. Chinese society of agricultural engineering, 2010.5

[3] Qu Fuguo, Sun Yufei. Study on payments for environmental services in basin area based on intergovernmental game. China population, resources and environment, 2014.11

[4] Ouyang Zhiyu, Zheng Hua, Yue Ping. Establishment of ecological compensation mechanisms in China: perspectives and strategies. Acta ecologica sinica, 2013.3 